\title{
1. Childcare, early education, and social inequality: Perspectives for a cross-national and multidisciplinary study
}

\author{
Nevena Kulic, Jan Skopek, Moris Triventi, and \\ Hans-Peter Blossfeld
}

\section{INTRODUCTION}

For a long time, sociological research has neglected social inequalities in the early educational experiences of children. Most sociological studies concentrated on the impact of socio-economic (and cultural) family conditions on children's educational outcomes in primary (for example, Gustafsson et al. 2011) and secondary school (for example, Marks et al. 2006; Blossfeld et al. 2016). Some focused further on the impact of family background on educational transitions in the school, vocational training, and university systems (Shavit and Blossfeld 1993; Jackson 2013) or on the role of final educational attainment for entry into the labour market (Blossfeld et al. 2015). Yet a growing body of research shows that children already differ markedly in basic cognitive skills and non-cognitive competencies (such as motivation, social skills, or persistence) before they enter school (Esping-Andersen 2004; Meyers et al. 2004; Heckman 2006; Bradbury et al. 2015). The degree to which hereditary predispositions are expressed and small children can develop their cognitive, social, and motivational potentials seems to depend strongly on the initial environmental conditions (Carneiro and Heckman 2003; Röder and Rösler 2014; UNICEF 2016). Very first experiences are normally shaped by different socio-economic and cultural conditions in the family, by different parental interactions and language stimulation at home, and by variations in parental engagement as well as educational investments in their children. Today, for instance, children may enrol in educational programmes very early, as shown in the rising attendance of preschool institutions. These differences in the initial conditions set the foundation for an individual's entire later 
life and often initiate long-term path dependencies in personal development (DiPrete and Eirich 2006). Consequently, understanding the factors that lead to achievement gaps in cognitive and non-cognitive development in early childhood and the potential to combat these early inequalities through educational policies are issues that are of great importance for an adequate grasp of the formation of social inequalities in the life course.

This book explores early steps in the educational career while focusing on the impact of early home environments, formal and informal childcare, and preschool enrolment on the diverging educational destinies of children. Until recently, concern about early educational investments was not on the political agenda because it was assumed that children are taken care of at home and that parental care was outside the scope of public policy. Consequently, parents were responsible for passing on skills and knowledge to their children. A massive reorientation towards external forms of care in the last decades has changed this perspective, and preschool education has become a source of skill creation early in life. In light of this, early education can also serve as an effective equalizer alleviating social inequalities in educational attainment. This book concentrates particularly on the childcare choices of families, the role of early parental involvement and care for educational success and achievement gaps, and, eventually, the consequences of early education and care for social inequality in educational opportunities. The book asks when, how, and why do social inequalities in abilities and skills arise in early life. It also asks what can be done in modern societies to combat the mechanisms producing early social inequality.

Several longitudinal studies focusing on children from very disadvantaged families have provided empirical evidence that early investments in education can effectively increase the cognitive and non-cognitive skills of these children and change their long-term educational and labour market opportunities (Barnett 1995; Heckman 2006). Disadvantaged children who have experienced preschool educational interventions tend to be more successful in school, are less often unemployed in adulthood, receive higher earnings, are less dependent on social welfare, have a lower crime rate, and live a healthier life than children without such experience (Burger 2010; Barnett 2011). However, are the effects of early investments in education confined mainly to children from very disadvantaged families? Do children from privileged middle or upper class families also gain from institutions of early childhood education? How far can gaps in cognitive skills and non-cognitive competencies among children from different family origins be narrowed effectively or even eliminated by adequate early educational interventions? Differential environments and exposure to different types of educational programmes are related to varying opportunities to deliver 
educational stimulation for children. Do advantaged families have a more privileged access to higher quality early childhood education institutions? If so, family decisions regarding childcare settings can be viewed as an important mechanism driving early inequalities (Vandell and Corasaniti 1990). Although the value of childcare goes beyond the provision of equal opportunities for children, the above questions are important for sociological research and educational policymaking today.

Answers to these questions are likely to depend on the cultural, historical, and institutional contexts of modern societies. Countries differ in the provision of maternity and parental leave, and this could have direct consequences on the time parents spend with their young children (Waldfogel 2006). Provision of childcare is not uniform across modern societies, and this influences parental choice, access to care, and early social inequalities in cognitive and non-cognitive development (Smeeding et al. 2011). Moreover, the organizational heterogeneity of early childhood education (in terms of children's age of entry, duration of programmes, intensity, coverage, and opening hours) (OECD 2012) is large both within and across advanced industrial societies. Programmes of early childhood education may also differ greatly in terms of quality - as measured by, for instance, the teacher-child ratio, teacher qualifications, or centre resources (Gambaro et al. 2014). Yet, most of the available empirical evidence comes from only a limited number of English-speaking countries.

In contrast to previous research, this book studies social inequality in relation to the cross-country complexity of arrangements in which children are cared for while acknowledging the specific role for the lives of children of early education provided by parents and early childhood institutions. We look at how inequalities are created through all forms of childcare and early education from parental care to external forms of care. We draw a distinction between care and education provided by parents, informal education and care in an informal setting (either paid or unpaid), and formal-centre-based care as provided within an institutional setting. For instance, parental care is provided by mothers and fathers based either in the home environment or outside the home, and it comprises time and material investments that they dedicate to their offspring. Informal care relates to care provided by grandmothers, grandfathers, and other relatives, but it can also contain home-based forms of childcare provided by au pairs, nannies, or babysitters. Formal childcare instead comprises organized activities provided by trained educators covering all age groups and taking different forms such as day care, kindergarten, preschool, or playgroups. Importantly the distinction between different forms of formal care is not uniform across countries, and it is the institutional dimension of childcare that is in common to all of these 
arrangements. The book distinguishes between three important periods of child development: infancy (age zero-one), toddlerhood (age onethree), and preschool age (age three-six). Each period is characterized by specific child developmental processes and calls for different forms of care arrangements. Whereas parental care is dominant in infancy, the composition of childcare is more diverse the older children become. Also, the participation rates in formal childcare show distinct patterns for children below and above the age of three - being, on average, considerably higher for the older age group. Furthermore, this volume views the timing of entry, the duration, and the quality of early care and education as important aspects that add to the heterogeneous nature of childcare arrangements. Quality is one of the major forms of differentiation of formal care particularly for those age groups for which coverage is almost universal. When applicable, we tend to study both stable characteristics of the childcare institutions known as structural quality, and the quality of the interactions between staff and children, known as process quality. However, quality is an important feature of other forms of care such as parental or informal arrangements, although the measures of quality in such cases might be different from those used in formal arrangements. Another form of differentiation involves the intensity of the use of childcare, such as part-time or occasional care in contrast to full-day coverage. Formal care may also be more or less flexible in terms of allowed age of entry, thereby influencing the total exposure of children. In this book, childcare arrangements and early education and care are often used interchangeably to encompass a variety of these options with or without their educational component.

This volume concentrates on mostly educational (cognitive) outcomes and is organized around three sets of topics that are important for understanding the role of early education and care for the process of social inequality in the life course and across modern societies, as follows.

\section{Patterns and Choices of Early Education and Care}

Depending on their needs, preferences, opportunities, and constraints, families will pursue different strategies for childcare involving different kinds of care in terms of type, quality, and intensity. We first ask what patterns of care arrangements are to be found in infancy and early childhood (preschool age) by children's social background. We also ask how different measures of social background (income, education, and social class) relate to the choice of early education and care. What is the role of mother's education? 


\section{Parental Care and Social Inequalities}

The second topic deals with the role of parental involvement and care in producing social disparities in cognitive and non-cognitive outcomes in infancy and earliest childhood. We ask what role parental social background plays in parental involvement. How does the earliest child-parent interaction relate to social background?

\section{Consequences of Early Education and Care}

The third topic deals with the consequences of early non-parental education and care for social inequalities in early and later educational outcomes. We ask the following questions: how do different types of childcare arrangements mitigate or strengthen inequalities in early and later educational achievement? Is non-parental care beneficial for children? How do different forms of childcare interact in creating early social inequalities? What role does the quality of formal childcare play in overall achievement and in reducing inequality? High-quality care may be of more benefit to children from disadvantaged families, but it may also be that low quality care is even more detrimental for their development (Vandell and Corasaniti 1990).

The book includes the country context of childcare settings. Most research on the consequences of early care and education is based on data from the United States and the United Kingdom - nations characterized by a very heterogeneous landscape of services that vary substantially in quality (for example, Vandell and Corasaniti 1990) and follow a strongly market-based approach (Kamerman and Waldfogel 2005). In contrast, early childhood programmes in Europe are usually much more standardized by state regulations, more homogeneous in their services, and provided more universally for children above three (for example, Italy, Germany, France) (Spiess et al. 2003). Yet, when it comes to ages below three, European childcare systems differ vastly in their organization, affordability, and availability (OECD 2012). Some countries have moved towards universal public childcare (for example, Scandinavian countries, France), whereas others have less formalized forms of childcare and combine both public and private provision (for example, the United Kingdom, Italy, Germany).

We present a selection of studies that take full advantage of the recent availability of national longitudinal and register data on early childhood. We adopt a multidisciplinary vision of early education and care by bundling together studies conducted by researchers from sociology, psychology, economics, and educational science. Each chapter in this volume 
covers one of the three topics in different national contexts. Twelve indepth country studies are presented that mostly adopt a longitudinal perspective on childcare arrangements and child outcomes. Country-specific case studies are complemented by a comparative chapter using crossnational datasets to investigate between- and within-country differences in the choice and consequences of early childcare arrangements.

\section{THE PATTERNS OF EARLY EDUCATION AND CARE AND CHILDREN'S SOCIAL BACKGROUND}

The first topic of the book is family decisions on childcare arrangements. Parents have various childcare options, and their choice shows how much they are committed to their child's development (Fuller et al. 1996). Parental decisions about the forms, timing, and intensity of childcare shape children's exposure to certain learning environments and, consequently, their opportunities for development. In addition, knowledge about the factors driving these decisions helps to explain their consequences for children's progress. Presuming that certain types of early education and care have different effects on early cognitive and non-cognitive outcomes, selection into these types determines who will benefit from these effects. On the other hand, parental decisions on childcare arrangements are not fully a matter of free choice but subject to constraints due to the availability and characteristics of different sorts of care (Early and Burchinal 2001). Hence, preferences for childcare are only part of a broader concept of selection into childcare.

Sociological literature conceives social inequality in educational opportunities as a dual phenomenon brought about by two analytically distinct but jointly operating mechanisms: primary effects and secondary effects of social origin (for a recent and comprehensive discussion, see Jackson 2013). Primary effects operate via origin-specific distributions in achievement and academic skills (Boudon 1974). On average, children from higher social backgrounds show higher academic performance and receive better marks in school. Secondary effects refer to educational choices that are found to vary by social background as a consequence of different educational aspirations, cost-benefit calculations, and/or status maintenance behaviour (Breen and Goldthorpe 1997; Jackson 2013). Much is known about the association between social background and school performance in primary and secondary school, but it is only recently that interest has grown in how social background affects early cognitive and non-cognitive outcomes. As mentioned above, first inequalities emerge at a very early age (Esping-Andersen 2004). What are the channels through which the 
social background operates at such an early age? How are early experiences linked to family differences in parental education, income, and social class - the cultural and material forms of capital that parents pass on to their children? How far do other factors such as the choice of preschool institutions play a role? In most industrialized countries, early care and education institutions have become the first important step in the educational career of individuals. Highly educated families place great value on education and early care, which, as a consequence, influences child performance (Waldfogel 2006). If advantaged families choose better educational environments for their children in later educational stages (Lucas 2001; Jackson 2013), they might also know how to make good choices in the earliest institutions of education and care.

Children from more advantaged families often gain more than less advantaged children from enrolment in kindergarten, particularly because they attend higher quality care institutions (Waldfogel 2006). This may explain why the most educated parents have a higher probability of sending their children to preschool programmes (Kim and Fram 2009). However, whereas there is a comprehensive literature explaining secondary effects of social origin at educational transitions in school, the question how parental social position and choices are interrelated in early childhood is still understudied.

Consequently, the literature on selection into different types of institutions of early education and care is quite underrepresented in the current state of research. Nonetheless, to gain an answer to the question how social inequality in education emerges at an early stage, it is vital to understand who is opting for different sorts of childcare and when they are doing this (Kim and Fram 2009). There are studies showing that socio-cultural features of the family still influence the choice and characteristics of childcare even after controlling for economic characteristics and employment (Fuller et al. 1996; Early and Burchinal 2001). Research has also found evidence that children from advantaged backgrounds are more likely to attend and spend longer time in centre-based care (Early and Burchinal 2001; Wolfe and Scrivner 2004; Waldfogel 2006), whereas children from lower social backgrounds are cared far more often in informal arrangements (Early and Burchinal 2001). Furthermore, the different preferences of highly educated parents are reflected through their choice of better quality childcare in situations in which formal childcare becomes more universal - for instance, for children above three and four. However, access to high-quality care may be limited for low-income families (Magnuson and Shager 2010; Chaudry et al. 2011). Beyond this, family background might be associated with both the timing of entry into care and the quality of informal care due to the links between the social position of parents 
and informal childminders (Del Boca et al. 2014). All these factors might bear consequences for children's differential exposure to certain educational environments in early childhood. Another important question is how far the behaviour of working and non-working mothers and fathers is changing over time (Sullivan et al. 2013).

Finally, participation of children in childcare may be differently related to parental income, education, and occupation. Material resources do not necessarily suffice in explaining (early) inequalities (Goldthorpe 2010), and social class and education might offer a better explanation for the transfer of cultural values in parent-child interactions (Gracia 2015). In addition, the quality of early parental care and decisions on the participation in early childcare, have often been seen as being related directly to mother's education. In many countries, mothers are still the primary caregivers in early childhood (Sayer et al. 2004), the major decision makers in childcare arrangements (Reay 1998), and the initiators of child attachment to the father (Gracia 2015). Most past studies focused on mothers' characteristics and they partly overlooked the combinations of both partners' resources. However, since both parents rely on their individual endowments in terms of education, income, or occupation, it is promising to also conceive social background as a combination of family resources rather than rely only on those of the mother. The different dimensions of social background distinctly influence the character of the interaction between parental care and parental choices regarding early childcare institutions.

In this volume, we acknowledge the importance of social background for choices and patterns of childcare arrangements. We expect to find that parental class, education, and income are related to the usage of childcare, although each of them might exhibit a distinct influence on childcare patterns. We argue that children from advantaged families are more likely not only to enrol earlier in centre-based care but also to more frequently attend better quality early education and care. We follow the argument that prevalent use of informal childcare is linked to the lower socio-economic status of families. Some of the general findings from the empirical work presented above are tested in this volume on a new set of countries in order to extend the existing evidence that comes mostly from the United States and English-speaking geographical contexts.

\section{PARENTAL CARE AND SOCIAL INEQUALITIES}

The second topic of this volume addresses the role of parental involvement and care for child development. Parental care is the first option available to families, and is typically predominant in the early months of children's 
lives. In early infancy, parental involvement incorporates sensitivity and responsiveness to the child's needs (Waldfogel 2006) and substantial physical care for babies and toddlers. Yet, child needs are dynamic in nature and vary strongly over the early years (Sacker et al. 2002). Consequently, the character of involvement changes over the course of development, shifting the focus from physical care towards stimulation of intellectual capacity and social behaviour (Gracia 2014). In particular, mothers have a decisive role because they can exert a primary influence on their children's abilities, early socialization, and development (Melhuish et al. 2001). Despite the empirical observation that the traditional time gap in childcare between mothers and fathers has been shrinking in recent years (Bianchi 2011), mothers still consistently spend more time with small children than fathers (Gracia 2014). As a consequence, mothers' characteristics play a major role in early development, particularly before children are placed in any form of external childcare arrangements.

Families with different social positions, however, seem to be unequal in the material and time investments in their children (Bianchi et al. 2004; Yoshida 2011). In addition, parental involvement and home environments are crucial dimensions in explaining why and how social background and child development are closely related in infancy and early childhood. Indeed, the empirical literature finds a strong relationship between social background, parental involvement, and both the cognitive and noncognitive achievement of children (Melhuish et al. 2001; Sacker et al. 2002; Anders et al. 2013).

First, as a result of increasing educational homogamy, families with a higher social position can nowadays more often fall back on highly educated mothers (Bianchi et al. 2004), and this has direct consequences for the children's upbringing. Sociological studies of time diary data found that highly educated mothers adapt particularly well to the growing needs of their children over the course of their development (Kalil et al. 2012), although more studies point to the increasing engagement of highly educated fathers in child-related activities - particularly among very young infants (Gershuny 2000; Gracia 2014). Even if women used to be major actors in securing childcare (Pungello and Kurtz-Kostes 1999), changes in the relative position of women might have rendered decisions on childcare more of a shared decision by a couple, thereby allowing fathers to spend more time with their children (Bianchi et al. 2004). At the same time, higher education of parents may also go along with a higher quality of care time and interaction with children that stimulates early cognitive development (Bianchi et al. 2004; Bonke and Esping-Andersen 2011). For instance, higher educated parents spend more time reading, playing, and engaging in out-of-home activities with their children (Sandberg and 
Hoffert 2001), and less time watching television or engaging in other rather passive activities (Bihagen and Katz-Gerro 2000).

Second, higher education of parents correlates with a more favourable socio-economic position of the family, implying the availability of more material resources to invest in the development of children. However, material benefits and child-related expenditures alone do not necessarily matter for children's development (Bianchi et al. 2004). Research suggests that it is predominantly differences in child-parent interaction and different childrearing practices (Mayer 1997) that distinguish between families of different social backgrounds in terms of the quality of parental care. For instance, Lareau (2003) identified class-specific parenting practices in promoting school-related skills that have been labelled as 'concerted cultivation'. These are pursued by middle and upper class parents in contrast to the 'natural growth approach' adopted usually by working class parents. Other researchers, however, suggest that sensitivity of parents and parental interaction are important in early life, but are closely linked to the direct material situation of parents (Waldfogel 2006). It is the combination of parent-child interactions and activities as well as material conditions at home that seems to correlate within certain social backgrounds (Epstein 2001).

What consequences do different models of parental involvement have for reproducing social inequalities in children's educational opportunities and achievement? Privileged families may pass on their economic and cultural capital directly through involvement with their children. Whereas policies directed towards increasing family income and parental employment opportunities might influence the material situation of children, inequality in child development resulting from the transmission of cultural capital, specific lifestyles, and intellectual stimulation are much harder to change. However, the quality of parental care and the transmission of privilege in early years often conflict with the opportunity costs of not working (Becker 1981). More educated parents and particularly more educated mothers are more likely to be engaged in employment, and therefore have less time to dedicate to joint activities with their children. Hence, the final impact of better quality parental care depends on the interplay between the quality of both external care and parental care.

Following various studies presented above, we start this volume by developing a general expectation that advantaged families are more likely to invest in quality time with their children. The children also profit from the prior knowledge (and means) of their parents about activities that are best for their cognitive development. Different contributions in this volume decompose the principal dimensions of parental care, and study those that are most related to social background. 


\section{THE CONSEQUENCES OF NON-PARENTAL EDUCATION AND CARE FOR SOCIAL INEQUALITIES IN EARLY AND LATER INDIVIDUAL OUTCOMES}

The third topic addresses how formal and informal childcare arrangements influence individual achievement, and it concentrates on their role in the achievement gaps between children of different social backgrounds. By distinguishing between different types of non-parental education and care, we also acknowledge that there might be differences in outcome between informal and formal care (Gupta and Simonsen 2010). Moreover, the quality of either formal or informal care may also affect various child outcomes (Del Boca 2015a). One could assume that informal childcare is likely to be less beneficial when used as a surrogate for the formal childcare that is usually associated with a more educationally stimulating environment. However, if the grandparents are the major source of informal childcare, the socio-economic status of the family is also an important moderating variable for child development.

\section{Early Formal Education and Social Inequality}

Numerous studies have shown that early education and care in institutional settings can improve children's skills and abilities and have potentially long-lasting effects on their life chances (for reviews, see Barnett 1995; Burger 2010). Most robust empirical evidence comes from experimental studies on model programmes with random assignment of participants. In addition, there is also much literature on medium- to large-scale public programmes, often deriving from birth cohort studies (see Burger 2010). Many findings indicate a positive influence of preschool education on the cognitive development of children (Magnuson et al. 2007; Burchinal et al. 2014), their high-school achievement, their behaviour, and their socialization (Gupta and Simonsen 2010), and that this influence is also long term (Campbell et al. 2001; Vandell et al. 2010). Experimental studies have found remarkably positive effects of preschool programmes on school readiness outcomes by randomly assigning children to Head Start programmes in the United States (Abbott-Shim et al. 2003). Negative results of early interventions are rare but also known: an experimental programme implemented in British Columbia had a negative impact on participating children, especially those from lower social backgrounds - both in the short and long term (DeCicca and Smith 2013). Sometimes, large-scale programmes are found to be slightly less effective as equalizers than high-quality model 
programmes that are often directed towards specific student groups (Barnett 1995; Currie 2001).

Important aspects of preschool attendance are factors related to exposure and the quality of programmes. For instance, age of entry, duration, intensity, and quality of early education programmes also matter (Burger 2010). Overall, enrolment at earlier ages is related positively to cognitive development, even if results on total exposure time are inconclusive. There is evidence that intensity of programmes (for example, full-day versus half-day) is more important than sheer duration, even if the latter may have an influence as well (for example, Landvoigt et al. 2007). Some studies find that extensive centre-based care particularly in infancy can be harmful for later achievement in school and social skills (Vandell and Corasaniti 1990). Also, more recent studies reveal that longer hours in non-parental care can lead to poorer child outcomes (Gupta and Simonsen 2010) or that staying longer hours in kindergarten may have adverse effects on later school performance (DeCicca and Smith 2013).

The issue of quality is crucial for studying inequality in early childhood (Meyer et al. 2004). It is the content, the structure, and the peers in highquality institutions that may enhance early development, and it is often the least advantaged who profit the least from the high quality of institutional care due to unequal access. Thus, many scholars argue that early interventions not only benefit individuals but can also contribute to alleviating social inequalities if high-quality care is promoted among lower class families (Del Boca 2015a). Vandell et al. (2010) found that positive effects of preschool programmes may remain up to adolescence only if they are of good quality. Magnuson et al. (2007) also suggest that the quality of programmes affects the impact of formal childcare on cognitive and non-cognitive development, and that this is particularly true for disadvantaged children.

In general, when measuring the quality of preschool programmes, the literature distinguishes between structural and process quality. The first relates to rather stable characteristics of the childcare institutions such as the teacher-child ratio, the centre's resources, and the teachers' qualifications. Process quality measures cover the quality of the institutional environment in terms of the interactional outcomes between children and educators. Accounting for variation in quality turns out to be crucial for assessing the effectiveness of preschool education in day care centres and kindergartens (Vandell et al. 1988; Vandell and Corsaniti 1990; Meyers et al. 2004).

In line with some of the evidence presented, different contributions in this volume test whether early education and care in institutional settings improves children's skills and abilities, and analyse the role of preschool quality. 


\section{Are the Effects of Early Education and Care Lasting?}

Only a limited number of studies have focused on whether preschool effects are lasting or may diminish as children progress through their educational careers in primary and secondary school. To mention some of this research, Belsky et al. (2007) report lasting effects of higher quality care in the fifth grade in school, although parenting was found to be a stronger and more consistent predictor of children's development than the experience of early childhood education. Indeed, reducing social inequalities in educational opportunity through preschool education might be effective only if early gains and compensatory effects translate into effects that persist at least until the end of primary school (for example, via path-dependent or cumulative learning effects). The evaluation of long-term effects of programmes is often problematic, and conclusions are thus limited to the very small populations that took part in the experimental studies (Barnett 1995). Barnett (ibid.) reports that the most reliable results on long-term effects of preschool come from the Perry Preschool Program - an experimental early childhood education programme that targeted 123 children from very poor families (mostly single mothers of African origin) in the Michigan area. Also, many quasi-experimental studies (for example, the German Socio-Economic Panel, SOEP, the National Child Development Study, NCDS, and the British Cohort Study, BCS) focused mainly on quite disadvantaged populations, whereas some others were designed to encompass a large range of children (for example, Effective Provision of Preschool Education, EPPE). In this volume, several chapters address the theoretical expectation that the effects of early education and care persist (Heckman 2006).

Finally, children from various backgrounds may benefit differently from early educational programmes. Thus, could formal care compensate inequalities among children from different social backgrounds? The literature finds that the most disadvantaged children bear a double burden in their development: they are less likely to have a highly stimulating home environment to fall back on, and they are less likely to benefit from highquality early education (Meyers et al. 2004) because they have less access to it. Social background often serves to mediate and moderate the effects of early formal care, implying the existence of heterogeneous effects by social background.

Some of the programme evaluations show empirical evidence that preschool compensates for a poor home environment, although many studies also find that full compensation is not always feasible (Burger 2010). For example, evidence from a German study on the effect of kindergarten attendance on secondary schooling shows a compensatory effect 
only for migrant children (Spiess et al. 2003). Another recent study from Germany (Felfe and Lalive 2013) found compensatory effects of highquality centre-based care on inequalities in a wide range of skills across children. Although children from more advantageous backgrounds are more likely to be enrolled in high-quality centre-based care, they profit the least; whereas children from less advantageous backgrounds are less likely to attend, but gain the most. Also, the evidence from the EPPE programme, a longitudinal study following up children's development from age three to age seven in the United Kingdom (Siraj-Blatchford et al. 2011; Sylva et al. 2012), suggests that promoting preschool participation of children from less advantageous backgrounds may be effective in reducing social inequalities in children's development. However, research also suggests that compensatory effects or accumulation effects are not found that often (Esping-Andersen et al. 2012). In this volume, we start from a general expectation that better quality care and preschool systems alleviate inequalities in cognitive development, enabling a compensatory effect of (formal) childcare.

\section{Informal Childcare Arrangements}

The majority of recent studies have focused on the effects of parental and formal non-parental care, whereas informal care has been much less studied in the literature. Although all of the contributions in this volume tackle the consequences of formal and parental care, understanding the role that informal care can play in social inequality is essential for a comprehensive approach. Below we review some of the most important work.

By far the most dominant source of informal childcare is grandparents. Comparative studies found that European grandparents are an indispensable source of childcare provision even when overall levels of grandparental childcare - roughly following a north-south divide in Europe - are moderated by the family policies of welfare states (Hank and Buber 2009; Leopold and Skopek 2014). Similarly, reiterated reports from the United States have shown that grandparents play an increasingly decisive role especially if the mother is working - in minding children at preschool age (Laughlin 2013).

Like formal care, informal childcare might be related to child outcomes in cognitive and non-cognitive terms. However, not much is known about the consequences of informal care for children's achievement and future life chances. Only a few studies explicitly address the role of informal care and grandparents in the early development of children (Fergusson et al. 2008; Hansen and Hawkes 2009; Bernal and Keane 2011; Del Boca et al. 2014). The few results are rather equivocal. For instance, whereas Del Boca 
et al. (2014) found that care by grandparents may improve vocabulary skills, it is negatively associated with problem solving or mathematical concepts. Hansen and Hawkes (2009) suggest that grandparents could even promote certain forms of behaviour problems. Importantly, heterogeneous effects have also been found in both studies: grandparental care was found to be beneficial only in terms of vocabulary for children from more advantaged family backgrounds (measured in terms of higher education of the mother). Therefore, in general, children from disadvantaged family backgrounds seem to be penalized even more when formal childcare is replaced by informal (family) care, whereas this does not hold for children from more advantageous family backgrounds. In comparison, Bernal and Keane (2011) found a negative effect of external care driven mainly by the high usage of informal childcare (for example, grandparents and relatives) that turned out to have adverse effects on cognitive achievement as compared to formal early childhood education. Furthermore, the adverse effect of external childcare was found to be larger for children of higher educated mothers, with a substitution of high-quality maternal time through informal or formal care alternatives being more penalizing. Finally, many studies show that grandparents also play an important role in the process of social mobility (Falbo 1991; Erola and Moisio 2006; Modin et al. 2013) due to non-negligible correlations between grandparents' characteristics and child outcomes at later stages of their life.

\section{THE RELEVANCE OF COUNTRY CONTEXTS}

Enrolment rates in formal childcare vary largely across countries, and their degree of cross-national variation also depends on the children's age. Data from the OECD (2012) indicate that there is much more variation in the proportion of children attending formal early childhood education and care (ECEC) in early childhood than in preschool age. Among children aged three to five, in many European countries the proportion attending formal childcare exceeds 90 per cent. Among the economically developed countries, the United States represents an exception, because formal childcare in preschool years is underdeveloped, reaching only two-thirds of children in the respective age span.

Families' decisions on how to care for their young children are presumably the result of both cultural preferences and considerations stemming from the rational assessment of the costs and benefits associated with formal childcare versus the alternatively available unpaid options (for example, parental care or other forms of informal care). The opportunity and constraints faced by families are defined within a broader institutional 
and societal setting that is highly dependent on countries' social policies and the dominant welfare regime (Esping-Andersen 1990; Arts and Gelissen 2002).

In our volume, we are interested not just in the overall access to formal childcare. We are also interested in who is more likely to rely on centrebased childcare, particularly in relation to the families' social position. Three theoretically important dimensions of welfare regimes seem to influence the main features of ECEC systems and the prevailing childcare arrangements adopted by families with different educational levels and economic resources (Van Lancker and Ghysels 2013). These are: (1) universalism, (2) decommodification, and (3) defamiliarization. In our context, universalism refers to the extent to which access to ECEC is guaranteed to the child who needs it; decommodification refers to the extent to which ECEC is offered as a public or private service. Finally, defamiliarization refers to the - more or less prominent - childcare role assigned by social policies to parents and the extended family.

With regard to the first dimension (universalism), countries differ in the extent to which they provide services for caring and educating children. Nowadays, in the Nordic countries (Denmark, Finland, Norway, and Sweden) and Estonia, children below age three possess a legal right to access formal childcare services. In contrast, in other contexts such as Southern European countries, this is not the case, and the rationing of ECEC services is an issue. When rationing of formal childcare occurs, its availability appears to be lower in more disadvantaged and lower income geographical areas (Henley and Lyons 2000) especially discouraging maternal employment supply of low-educated mothers (Del Boca and Vuri 2007). Therefore, one might expect social inequality in access to formal childcare services to be smaller in countries with a universalistic approach to the supply of ECEC services.

The second important dimension of childcare supply refers to the publicprivate mix of ECEC services. This is linked to the decommodification dimension of welfare regimes. Despite a general tendency towards increasing 'marketization' in the childcare field (Brennan et al. 2012), modern societies vary largely in the extent to which the public and the private sectors are engaged in providing childcare services (Van Lancker and Ghysels 2013). In some countries, formal childcare is based mainly on public provision and the private sector is very limited. This is the case in the Nordic countries where the state is directly involved in the provision of childcare in order to guarantee universal access. In other countries, such as the United States and the United Kingdom, the private sector plays a more central role and accounts for a large share of the ECEC supply. In these countries, childcare centres are traditionally of a higher quality than the informal types of 
childcare provided by grandparents or nannies (Brilli et al. 2013). However, research also shows that private childcare provision is generally characterized by a larger heterogeneity in quality compared to public services, higher costs for families, and problems of rationing - especially in poor areas (OECD 2012). In some countries in Southern Europe such as Italy, a mixed public-private childcare supply has been developed with regulations on minimum quality standards that all providers have to meet.

Together with the degree of private provision of childcare, the level of government investment and intervention may also be important for ensuring equal access to formal childcare to families from different socioeconomic strata. The total public spending in ECEC services as a percentage of GDP is larger in Nordic European countries, followed by the United Kingdom and the Netherlands. It is much smaller in Italy, Germany, and especially the United States. Most countries spend more on preschool care than early childcare, which, as suggested by the OECD, could partly be a reflection of coverage of a larger age group and a higher enrolment rate. There is relatively limited country variation in public spending on early education of three to five year olds, whereas the variation is higher for spending on formal childcare per child under the age of three.

In countries with low government intervention, high-quality facilities will be expensive because the high production costs (higher staff wages and qualifications along with a lower staff-child ratio) do not receive adequate public subsidies. The affordability of services is an important driver of families' decisions about childcare and may also be related to social inequalities in access to formal childcare services. Indeed, empirical evidence suggests that the impact of childcare costs is greater for mothers with lower earnings potential, such as those with lower levels of education (Baum 2002). Therefore, ceteris paribus, in countries where the affordability of formal childcare is lower because of higher costs and/or poor publicly available subsidies, it is likely that one will observe larger social inequalities in access.

Government spending could also relate to the quality of the formal childcare provision. Quality of childcare involves many aspects such as standards of hygiene and safety, staff-child ratios, staff experience and qualifications, type of activities engaged in with the children, and so on. Even if data on all these aspects are not currently available in a comparative perspective, information on the staff-child ratio - which gives a quantitative indication of the frequency of contacts between educators and children - is provided by the OECD and Eurostat. Overall, the staff-child ratio is smaller in Nordic countries and in the United Kingdom, higher in Continental Europe, and highest in some Southern European countries such as Spain and Portugal. 
Finally, it is important to recognize that - beyond the characteristics of formal childcare supply - families may decide not to rely on formal childcare for a variety of reasons such as the availability of attractive parental care alternatives (for example, extended parental leave) or informal care (for example, grandparental care).

Parental care, which is most of the time maternal care, depends critically on whether the mother is employed or not. Despite an increase in the labour force participation rate of mothers of young and very young children in recent decades, there are still remarkable variations across industrialized societies: participation rates are highest in the Nordic countries (Denmark, Norway, Sweden), slightly lower in Central-Western European countries (for example, Germany, the Netherlands, France) and Anglophone countries (US, United Kingdom), and lowest in Southern European countries such as Italy and Greece (OECD 2015). Women's participation in the labour market is important in our context because it constrains the time mothers can spend with their children, and it often implies relying on external non-parental sources of childcare (Del Boca 2015b). More specifically, there is a reciprocal relationship between female employment and formal childcare supply: the availability of childcare services increases the propensity of mothers of young children to engage in paid employment, and this, in turn, may lead to a greater demand for childcare services (Steiber and Haas 2012; Van Lancker and Ghysels 2013). Given that employment participation varies by mothers' educational levels, we can expect smaller social inequalities in access to childcare services where participation in the labour market is less dependent on educational level and there are high employment levels among low-skilled mothers.

Parents' reliance on centre-based childcare in early childhood along with the quantity and quality of time that children spend with their parents may also depend critically on parental leave policies - in particular, their economic generosity and length. For example, generous periods of well-paid leave seem to be beneficial to maternal employment participation. In this context, indeed, young women are encouraged to strengthen their labour market attachment before pregnancy, because they can anticipate only minor income losses and smooth returns to their jobs afterwards. However, as suggested by Van Lancker and Ghysels (2013), in countries offering only limited public support for childcare services, long periods of leave could discourage female participation in the labour market and instead promote the traditional homemaker-breadwinner model. This should affect especially women with low levels of education and lower earnings potential, because they will have fewer economic incentives to return to work or enter the labour market. This might be expected to lead to larger social inequalities in access to formal childcare. 
Finally, access to centre-based childcare can be affected by the availability of other forms of informal childcare such as grandparents or extended family that may act as substitutes when parents are at work. The availability of informal childcare should be larger in countries where the role of family is highly valued, where there is a larger incidence of retired grandparents, and where there are higher levels of residential proximity between parents and grandparents. It is usually assumed that families with lower social position (lowly educated and with less income) will be more likely to opt for informal childcare when both parents are working, especially in contexts with a rationing of ECEC services and absence of adequate public financial support. One may therefore expect larger differences in access to formal childcare between families with different social positions in these contexts.

Based on these different institutional and historical contexts, the conclusions on the consequences of early education and care need to be embedded in specific country settings. Our goal in this volume is to understand how far results depend on particular country conditions, and if and how far the findings may be generalized beyond the national perspectives. Twelve country-specific studies and a cross-national comparative chapter aim to show more and less successful policies, and to contribute to a broader knowledge on how early inequalities in children's lives may emerge and develop across modern societies.

\section{CONTRIBUTIONS IN THIS VOLUME}

We have organized the remaining chapters of the volume into several sections in line with our three major topics. Most chapters use carefully selected longitudinal datasets. Some studies even exploit register data on childcare choices. The majority of contributions explore selection into and consequences of early education and care. However, some chapters assess disparities in early cognitive ability markers among infants or are dedicated explicitly to choices in childcare. Other chapters take a long-term perspective by studying the association between childcare arrangements and educational outcomes in adolescence and young adulthood.

A first set of three chapters is devoted explicitly to patterns of childcare arrangements. In that regard, based on pooled data from the Italian Survey on Births (ISTAT), Brilli, Kulic, and Triventi analyse the relationship between families' social positions and the arrangements of childcare they opt for. This is followed by Kosyakova and Yastrebov who exploit the Russian Longitudinal Monitoring Survey (RLMS) and investigate the nexus between social policy reforms and unequal access to childcare 
in post-Soviet Russia. Viklund and Duvander draw upon administrative data from the Swedish Social Insurance Agency to study timing of children's entrance to preschool education and how this relates to parental socio-economic position.

A second set of chapters is dedicated to the quality of parental care and its consequences for social inequality in child development. Using recent longitudinal data from the newborn cohort of the German National Educational Panel Study (NEPS), Weinert, Attig, and Roßbach's chapter scrutinizes earliest social disparities in cognitive and non-cognitive development in infancy. Notably, they study whether mother-child interactions are structured by maternal education. McGinnity, McMullin, Murray, and Russell continue by studying the role of home learning environments and activities for children's language skills at age five in Ireland. They base their study on panel data recently available from the Growing Up in Ireland Study.

A third and larger set of chapters tackles the consequences of non-parental care and preschool education for early and later educational outcomes. In an explicitly cross-national comparative chapter, Dämmrich and EspingAndersen combine data from the Progress in International Reading Literacy Study (PIRLS) and the Programme for International Student Assessment (PISA) to study consequences of preschool attendance for reading competencies based on harmonized data. Barnett and Frede provide an evaluative report on the successful implementation of a highquality preschool programme in the United States, the Abbott Pre-K program. In particular, they highlight the very features of quality that are crucial to make such a programme effective. Exploiting data from the Dutch Pre-COOL study, Leseman and colleagues study the role of quality aspects of institutions in ECEC for the cognitive and language development of disadvantaged children. Based on the Behavior Outlook Norwegian Developmental Study (BONDS), Zachrisson, Dearing, Blömeke, and Moser evaluate features of the Norwegian model of ECEC with regard to its capacity to improve the relative position of socio-economically disadvantaged children. Drawing on data from the Millennium Cohort Study in the United Kingdom, Del Boca, Piazzalunga, and Pronzato study the effects of early childcare on cognitive outcomes of children and the role of early childcare for overall social inequality in early educational outcomes. This is followed by Skopek's study that analyses the consequences that the timing of centre-based care has for social disparities in language skills among preschool-aged children in East and West Germany - using recent data from the NEPS preschooler cohort. The collection of studies closes with two chapters focusing on longer-term consequences of non-parental early education and care. Wahler, Buchholz, and Breinholt for Denmark 
(based on the Danish Longitudinal Survey of Children, DALSC) and Karhula, Erola, and Kilpi-Jakonen for Finland (based on Finnish register data) assess the consequences of childcare arrangements on later educational outcomes of children.

The book closes with a chapter summarizing the theoretical and empirical insights gained from the earlier chapters and drawing several major conclusions on the role of childcare and early education in modern societies.

\section{REFERENCES}

Abbott-Shim, M., R. Lambert and F. McCarty (2003), 'A comparison of school readiness outcomes for children randomly assigned to a Head Start programme and the programme's wait list', Journal of Education for Students Placed at Risk, 8(2), 191-214.

Anders, Y., C. Grosse, H.G. Rossbach, S. Ebert and S. Weinert (2013), 'Preschool and primary school influences on the development of children's early numeracy skills between the ages of 3 and 7 years in Germany', School Effectiveness and School Improvement, 24(2), 195-211.

Arts, W. and J. Gelissen (2002), 'Three worlds of welfare capitalism or more? A state-of-the-art report', Journal of European Social Policy, 12(2), 137-58.

Barnett, W.S. (1995), 'Long-term effects of early childhood programmes on cognitive and school outcomes', The Future of Children, 5(3), 25-50.

Barnett, W.S. (2011), 'Effectiveness of early educational intervention', Science, 333(6045), 975-78.

Baum, C.L. (2002), 'A dynamic analysis of the effect of child care costs on the work decisions of low-income mothers with infants', Demography, 39(1), 139-64.

Becker, G. (1981), A Treatise on the Family, Cambridge, MA: Harvard University Press.

Belsky, J., D.L. Vandell, M.R. Burchinal, K.A. Clarke-Stewart, K. McCartney and M.T. Owen (2007), 'Are there long-term effects of early child care?', Child Development, 78(2), 681-701.

Berger, L.M., J. Hill and J. Waldfogel (2005), 'Maternity leave, early maternal employment and child health and development in the US', The Economic Journal, 115(501), F29-F47.

Bernal, R. and M.P. Keane (2011), 'Child care choices and children's cognitive achievement: The case of single mothers', Journal of Labor Economics, 29(3), 459-512.

Bianchi, S.M. (2011), 'Family change and time allocation in American families', The ANNALS of the American Academy of Political and Social Science, 638(1), 21-44.

Bianchi, S., P. Cohen, S. Raley and K. Namagushi (2004), 'Inequality in parental investment in child-rearing: Expenditures, time, and health', in K. Neckerman (ed.), Social Inequality, New York: Russell Sage Foundation, pp. 189-219.

Bihagen, E. and T. Katz-Gerro (2000), 'Culture consumption in Sweden: The stability of gender differences', Poetics, 27(5), 327-49. 
Blossfeld, H.-P., S. Buchholz, J. Skopek and M. Triventi (2016), Models of Secondary Education and Social Inequality: An International Comparison, Cheltenham, UK and Northampton, MA, USA: Edward Elgar Publishing.

Blossfeld, H.-P., J. Skopek, M. Triventi and S. Buchholz (2015), Gender, Education and Employment: An International Comparison of School-to-Work Transitions, Cheltenham, UK and Northampton, MA, USA: Edward Elgar Publishing.

Bonke, J. and G. Esping-Andersen (2011), 'Family investments in children productivities, preferences, and parental child care', European Sociological Review, 27(1), 43-55.

Boudon, R. (1974), Education, Opportunity, and Social Inequality: Changing Prospects in Western Society, New York; London: Wiley.

Bradbury, B., M. Corak, J. Waldfogel and E. Washbrokk (2015), Too Many Children Left Behind: A Cross-National Perspective on the United States Achievement Gap, New York: Russell Sage Foundation.

Breen, R. and J.H. Goldthorpe (1997), 'Explaining educational differentials: Towards a formal rational action theory', Rationality and Society, 9(3), 275-305.

Brennan, D., B. Cass, S. Himmelweit and M. Szebehely (2012), 'The marketisation of care: Rationales and consequences in Nordic and liberal care regimes', Journal of European Social Policy, 22(4), 377-91.

Brilli, Y., D. Del Boca and C. Monfardini (2013), 'Child care arrangements: Determinants and consequences', Families and Societies Working Paper Series, 2(2013).

Burchinal, M.R., J.E. Roberts, R. Riggin, S. Zeisel, E. Neebe and D. Bryant (2014), 'Relating quality of center-based child care to early cognitive and language development longitudinally', Child Development, 71(2), 339-57, doi:10.1111/1467-8624.00149.

Burger, K. (2010), 'How does early childhood care and education affect cognitive development? An international review of the effects of early interventions for children from different social backgrounds', Early Childhood Research Quarterly, 25(2), 140-65.

Campbell, F.A., E.P. Pungello, S. Miller-Johnson, M. Burchinal and C.T. Ramey (2001), 'The development of cognitive and academic abilities: Growth curves from an early childhood educational experiment', Developmental Psychology, 37(2), 231-42.

Carneiro, P. and J.J. Heckman (2003), 'Human capital policy', in J.J. Heckman, A.B. Krueger and B.M. Friedman (eds), Inequality in America: What Role for Human Capital Policies?, Cambridge, MA: MIT Press, 77-239.

Chaudry, A., J.M. Pedroza, H. Sandstrom, A. Danzinger, M. Grosz, M. Scott and S. Ting (2011), Child Care Choices of Low-Income Working Families, Washington: Urban Institute, accessed 24 June 2016 at http://www.urban.org/ sites/default/files/alfresco/publication-pdfs/412343-Child-Care-Choices-of-LowIncome-Working-Families.PDF.

Currie, J. (2001), 'Early childhood education programmes', Journal of Economic Perspectives, 15(2), 213-38.

DeCicca, P. and J. Smith (2013), 'The long-run impacts of early childhood education: Evidence from a failed policy experiment', Economics of Education Review, 36(C), 41-59.

Del Boca, D. (2015a), 'Childcare choices and child development', IZA World of Labor, accessed 24 June 2016 at http://wol.iza.org/articles/childcare-choicesand-child-development-1.pdf. 
Del Boca, D. (2015b), Child Care Arrangements and Labor Supply (No. 88074), Inter-American Development Bank, accessed 24 June 2016 at https://publica tions.iadb.org/.

Del Boca, D., D. Piazzalunga and C. Pronzato (2014), 'Early child care and child outcomes: The role of grandparents. Evidence from the Millennium Cohort Study', Families and Societies Working Paper Series, 20(2014).

Del Boca, D. and D. Vuri (2007), 'The mismatch between employment and child care in Italy: The impact of rationing', Journal of Population Economics, 20(4), 805-32.

DiPrete, T.A. and G.M. Eirich (2006), 'Cumulative advantage as a mechanism for inequality: A review of theoretical and empirical developments', Annual Review of Sociology, 32, 271-97.

Early, D.M. and M.R. Burchinal (2001), 'Early childhood care: Relations with family characteristics and preferred care characteristics', Early Childhood Research Quarterly, 16(4), 475-97.

Epstein, J. (2001), School, Family and Community Partnerships: Preparing Educators and Improving Schools, Boulder, CO: Westview Press.

Erola, J. and P. Moisio (2006), 'Social mobility over three generations in Finland, 1950-2000', European Sociological Review, 23(2), 169-83, doi:10.1093/esr/jc1027.

Esping-Andersen, G. (1990), The Three Worlds of Welfare Capitalism, Princeton: Princeton University Press.

Esping-Andersen, G. (2004), 'Untying the Gordian knot of social inheritance', Research in Social Stratification and Mobility, 21, 115-38.

Esping-Andersen, G., I. Garfinkel, W.-J. Han, K. Magnuson, S. Wagner and J. Waldfogel (2012), 'Child care and school performance in Denmark and the United States', Children and Youth Services Review, 34(3), 576-89.

Falbo, T. (1991), 'The impact of grandparents on children's outcomes in China', Marriage \& Family Review, 16(3-4), 369-76, doi:10.1300/J002v16n03_09.

Felfe, C. and R. Lalive (2013), 'Early child care and child development: For whom it works and why', SOEP Papers on Multidisciplinary Panel Data Research, Working Paper No. 536.

Fergusson, E., B. Maughan and J. Golding (2008), 'Which children receive grandparental care and what effect does it have?', Journal of Child Psychology and Psychiatry and Allied Disciplines, 49(2), 161-9, doi:10.1111/j.1469-7610.2007.01840.

Fuller, B., S.D. Holloway and X. Liang (1996), 'Family selection of child-care centers: The influence of household support, ethnicity, and parental practices', Child Development, 67(6), 3320-37.

Gambaro, L., K. Stewart and J. Waldfogel (eds) (2014), An Equal Start? Providing Quality Early Education and Care for Disadvantaged Children, Bristol: Policy Press.

German National Academy of Sciences Leopoldina, (2014), Socialisation in Early Childhood. Biological, Psychological, Linguistic, Sociological and Economic Perspectives, Berlin: German National Academy of Sciences Leopoldina.

Gershuny, J.I. (2000), Changing Times: Work and Leisure in Postindustrial Society, Oxford: Oxford University Press.

Goldthorpe, J.H. (2010), 'Analysing social inequality: A critique of two recent contributions from economics and epidemiology', European Sociological Review, 26(6), 731-44.

Gracia, P. (2014), 'Fathers' child care involvement and children's age in Spain: A time use study on differences by education and mothers' employment', European Sociological Review, 30(2), 137-50. 
Gracia, P. (2015), 'Parent-child leisure activities and cultural capital in the United Kingdom: The gendered effects of education and social class', Social Science Research, 52, 290-302.

Gupta, N.D. and M. Simonsen (2010), 'Non-cognitive child outcomes and universal high quality child care', Journal of Public Economics, 94(1), 30-43.

Gustafsson, J.E., K. Yang Hansen and M. Rosén (2011), 'Effects of home background on student achievement in reading, mathematics, and science at the fourth grade', in TIMSS and PIRLS 2011 Relationship Report, 181-287.

Hank, K. and I. Buber (2009), 'Grandparents caring for their grandchildren: Findings from the 2004 Survey of Health, Ageing, and Retirement in Europe', Journal of Family Issues, 30(1), 53-73.

Hansen, C. and D. Hawkes (2009), 'Early childcare and child development', Journal of Social Policy, 38(2), 211-39.

Heckman, J.J. (2006), 'Skill formation and the economics of investing in disadvantaged children', Science, 312(5782), 1900-2.

Henley, J.R. and S. Lyons (2000), 'The negotiation of child care and employment demands among low-income parents', Journal of Social Issues, 56(4), 683-706.

Jackson, M. (2013), Determined to Succeed? Performance Versus Choice in Educational Attainment, Stanford: Stanford University Press.

Kalil, A., R. Ryan and M. Corey (2012), 'Diverging destinies: Maternal education and the developmental gradient in time with children', Demography, 49(4), 1361-83.

Kamerman, S.B. and J. Waldfogel (2005), 'Market and non-market institutions in early childhood education and care', in R. Nelson (ed.), Market and Non-Market Institutions, New York: Russell Sage Foundation, pp. 185-212.

Kim, J. and M.S. Fram (2009), 'Profiles of choice: Parents' patterns of priority in child care decision-making', Early Childhood Research Quarterly, 24(1), 77-91.

Landvoigt, T., G. Mühler and F. Pfeiffer (2007), 'Duration and intensity of kindergarten attendance and secondary school track choice', $Z E W$-Centre for European Economic Research, Discussion Paper No. 07-051.

Laughlin, L. (2013), 'Who's minding the kids? Child care arrangements: Spring 2011', Household Economic Studies, United States Census Bureau, 70-135.

Lareau, A. (2003), Unequal Childhoods: Race, Class and Family Life, Berkeley: University of California Press.

Leopold, T. and J. Skopek (2014), 'Gender and the division of labor in older couples: How European grandparents share market work and childcare', Social Forces, 93(1), 63-91.

Lucas, S.R. (2001), 'Effectively maintained inequality: Education transitions, track mobility, and social background effects', American Journal of Sociology, 106(6), 1642-90.

Magnuson, K., C. Ruhm and J. Waldfogel (2007), 'Does prekindergarten improve school preparation and performance?', Economics of Education Review, 26(1): $33-51$.

Magnuson, K. and H. Shager (2010), 'Early education: Progress and promise for children from low-income families', Children and Youth Services Review, 32(9), 1186-98.

Marks, G.N., J. Cresswell and J. Ainley (2006), 'Explaining socioeconomic inequalities in student achievement: The role of home and school factors', Educational Research and Evaluation, 12(2), 105-28. 
Mayer, S. (1997), What Money Can't Buy: Family Income and Children's Life Chances, Cambridge, MA: Harvard University Press.

Melhuish, E., C. Sylva, P. Sammons, I. Siraj-Blatchford and B. Taggart (2001), 'Social behavioural and cognitive development at 3-4 years in relation to family background', The Effective Provision of Pre-School Education (EPPE) Project: Technical Paper 7, DfEE, London: The Institute of Education.

Meyers, M., D. Rosenbaum, C. Rhum and J. Waldfogel (2004), 'Inequality in early childhood education and care: What do we know?', in K. Neckerman (ed.), Social Inequality, New York: Russell Sage Foundation.

Modin, B., R. Erikson and D. Vågerö (2013), Intergenerational continuity in school performance: Do grandparents matter?', European Sociological Review, 29(4), 858-70.

OECD (2012), Starting Strong III - A Quality Toolbox for Early Childhood Education and Care, Paris: OECD.

OECD (2015), OECD Family database, accessed 25 June 2016 at www.oecd.org/ social/family/database.htm.

Pungello, E.P. and B. Kurtz-Costes (1999), 'Why and how working women choose child care: A review with a focus on infancy', Developmental Review, 19(1), 31-96.

Reay, D. (1998), 'Engendering social reproduction: mothers in the educational marketplace', British Journal of Sociology of Education, 19(2), 195-209.

Röder, B. and F. Rösler (2014), Frühkindliche Sozialisation: Biologische, Psychologische, Linguistische, Soziologische und Ökonomische Perspektiven [Socialization in Early Childhood: Biological, Psychological, Linguistic, Sociological and Economic Perspectives], Halle, Germany: Leopoldina.

Sacker, A., I. Schoon and M. Bartley (2002), 'Social inequality in educational achievement and psychosocial adjustment throughout childhood: Magnitude and mechanisms', Social Science \& Medicine, 55(5), 863-80.

Sandberg, J.F. and S.L. Hofferth (2001), 'Changes in children's time with parents: United States, 1981-1997', Demography, 38(3), 423-36.

Sayer, L.C., A.H. Gauthier and F.F. Furstenberg (2004), 'Educational differences in parents' time with children: Cross-national variations', Journal of Marriage and Family, 66(5), 1152-69.

Shavit, Y. and H.P. Blossfeld (1993), Persistent Inequality: Changing Educational Attainment in Thirteen Countries, Social Inequality Series, Boulder, CO: Westview Press.

Siraj-Blatchford, I., A. Mayo, E. Melhuish, B. Taggart, P. Sammons and K. Sylva (2011), Performing Against the Odds: Developmental Trajectories of Children in the EPPSE 3-16 study, Project Report, London: Department for Education.

Smeeding, T., R. Erikson and M. Jantti (2011) (eds), Persistence, Privilege and Parenting: The Comparative Study of Intergenerational Mobility, New York: Russell Sage Foundation.

Spiess, K.C., F. Büchel and G.G. Wagner (2003), 'Children's school placement in Germany: Does Kindergarten attendance matter?', Early Childhood Research Quarterly, 18(2), 255-70.

Steiber, N. and B. Haas (2012), 'Advances in explaining women's employment patterns', Socio-Economic Review, 10(2), 343-67.

Sullivan, A., S. Ketende and H. Joshi (2013), 'Social class and inequalities in early cognitive scores', Sociology, 47(6), 1187-206.

Sylva, K., E. Melhuish, P. Sammons, I. Siraj-Blatchford, B. Taggart, S. Hunt 
and H. Jelisic (2012), The Effect of Starting Pre-School at Age 2 on Long Term Academic and Social-Behavioural Outcomes in Year 6 for More Deprived Children, London: Institute of Education, University of London.

UNICEF Office of Research (2016), 'Fairness for children: A league table of inequality in child well-being in rich countries', Innocenti Report Card 13, UNICEF Office of Research - Innocenti, Florence.

Vandell, D.L., J. Belsky, M. Burchinal, L. Steinberg, N. Vandergrift and NICHD Early Child Care Research Network (2010), 'Do effects of early child care extend to age 15 years?', Child Development, 81(3), 737-56.

Vandell, D.L. and M.A. Corasaniti (1990), 'Variations in early child care: Do they predict subsequent social, emotional, and cognitive differences?', Early Childhood Research Quarterly, 5, 555-72.

Vandell, D.L., V.K. Henderson and K.S. Wilson (1988), 'A longitudinal study of children with day-care experiences of varying quality', Child Development, 59(5), 1286-92.

Van Lancker, W. and J. Ghysels (2013), 'Great expectations, but how to achieve them? Explaining patterns of inequality in childcare use across 31 developed countries', Working Paper No. 1305, Herman Deleeck Centre for Social Policy, University of Antwerp.

Yoshida, A. (2011), 'Dads who do diapers: Factors affecting care of young children by fathers', Journal of Family Issues, 33(4), 451-77.

Waldfogel, J. (2006), What Children Need, Cambridge, MA: Harvard University Press.

Wolfe, B. and S. Scrivner (2004), 'Child care use and parental desire to switch care type among a low-income population', Journal of Family and Economic Issues, 25(2), 139-62. 